\title{
Growth inhibitory effects of PC-NSAIDs on human breast cancer subtypes in cell culture
}

\author{
SHELLEY BURGE and LENARD M. LICHTENBERGER \\ Department of Integrative Biology and Pharmacology, McGovern Medical School at UTHealth, \\ The University of Texas Health Science Center at Houston, McGovern Medical School, Houston, TX 77030, USA
}

Received February 27, 2019; Accepted August 7, 2019

DOI: $10.3892 / \mathrm{ol} .2019 .10951$

\begin{abstract}
The potential role of non-steroidal anti-inflammatory drug (NSAID) therapy in the prevention and treatment of cancer has generated considerable research interest. Phosphatidylcholine (PC)-associated NSAIDs decrease the gastrointestinal side effects of NSAID therapy, and may be more effective than traditional NSAIDs in limiting tumor growth. In the present study, human cells representing three major breast cancer subtypes were cultured with aspirin, indomethacin and PC-associated forms of each drug, with $\mathrm{PC}$ alone as a control. All tested drugs decreased the tumor cell number after 8 days of culture, with PC-NSAIDs having the greatest inhibitory effect, and NSAIDs alone, particularly aspirin, having the least effect. PC alone was effective in limiting the proliferation of all cell lines, suggesting that the two components of PC-NSAIDs have an additive effect. The ELISA results did not support a strong role for inhibition of cyclooxygenase enzymes in the decrease in cancer cell proliferation, which may account for the limited effectiveness of aspirin alone. PC-NSAIDs, particularly indomethacin-PC, are attractive candidate drugs in the prevention and treatment of different types of breast cancer, including triple negative breast cancer.
\end{abstract}

\section{Introduction}

Aspirin and other non-steroidal anti-inflammatory drugs (NSAIDs) have been demonstrated to decrease the

Correspondence to: Dr Lenard M. Lichtenberger, Department of Integrative Biology and Pharmacology, McGovern Medical School at UTHealth, The University of Texas Health Science Center at Houston, McGovern Medical School, 6431 Fannin Street, Houston, TX 77030, USA

E-mail: lenard.m.lichtenberger@uth.tmc.edu

Abbreviations: NSAID, non-steroidal anti-inflammatory drug; PC, phosphatidylcholine; COX, cyclooxygenase; PGE2, prostaglandin E2; PLA2, phospholipase A2

Key words: aspirin, indomethacin, breast cancer, chemoprevention, non-steroidal anti-inflammatory drug incidence, progression and mortality of several types of cancer in randomized trials (1-4). As previously reported, phosphatidylcholine-associated NSAIDs (PC-NSAIDs) may be more effective than NSAIDs alone in inhibiting tumor growth in vitro and in vivo, in addition to their improved gastrointestinal safety relative to unmodified NSAIDs (5-8).

Several observational studies have demonstrated that NSAIDs were associated with decreased risk, recurrence and mortality in breast cancer (9-11); however, other cohort studies observed no effect $(12,13)$. A number of randomized controlled trials are currently underway that aim to investigate the effect of aspirin on the treatment and secondary prevention of breast cancer (14-16); these results should shed light on the inconsistent epidemiological data.

Breast tumors are classified into subtypes based on a number of factors, including hormone receptor status and amplification of the human epidermal growth factor receptor 2 (HER2) gene. These subtypes may reveal variations in cyclooxygenase $(\mathrm{COX})$ expression $(17,18)$ or other factors that impact their susceptibility to NSAID therapy. Limited observational and in vitro studies have investigated the response of specific breast cancer subtypes to NSAID therapy, but a consistent pattern has not yet been unveiled (19-22).

To the best of our knowledge, the antitumor effects of PC-NSAIDs in breast cancer have not been previously reported. Likewise, the potent NSAID, indomethacin, has been largely disregarded in breast cancer research, although it has been demonstrated to be highly effective against the growth of colon and pancreatic cancer both in vitro and in vivo $(5,23)$. Therefore, the present study was performed in order to investigate the inhibitory effect of NSAIDs and PC-NSAIDs in cell lines representing three major breast cancer subtypes. Antitumor activity was measured as a decrease in cell number following culture with aspirin, indomethacin and the PC-associated preparations of the two drugs.

\section{Materials and methods}

Preparation of test drugs. For the NSAID trials, aspirin was purchased from Solvay Pharmaceuticals and indomethacin from Spectrum Chemicals, Ltd. PC (S-100 from Lipoid LLC) was dissolved in chloroform (Thermo Fisher Scientific, Inc.), which was then evaporated under nitrogen at $22^{\circ} \mathrm{C}$. NSAID and PC stock solutions were prepared by diluting each drug 
in serum-free culture medium and sonicating for $20 \mathrm{~min}$ at $30^{\circ} \mathrm{C}$ in a bath-type sonicator. Aspirin-PC was prepared by combining the aforementioned stock solutions of aspirin and $\mathrm{PC}$ in serum-free medium at an equal mass ratio, and sonicating for an additional $10 \mathrm{~min}$. Indomethacin-PC was prepared by combining indomethacin and $\mathrm{PC}$ at a 1:2 mass ratio, dissolved in acetone (Thermo Fisher Scientific, Inc.). The acetone was then removed by vacuum processing using a rotary evaporator and stock solution prepared by dilution and sonication, as aforementioned. Complete descriptions of the drug preparation procedures are available in previous publications under patent $(5,24,25)$.

Cell culture. Human cell lines were selected and are presented in Table I. MCF-7, SK-BR-3 and MDA-MB-231 cells were obtained from the laboratory of Dr Jeffrey Chang at McGovern Medical School at UTHealth (Houston, TX, USA). MCF-7 and MDA-MB-231 cells were cultured in DMEM with 5\% fetal bovine serum (FBS; Thermo Fisher Scientific, Inc.), and SK-BR-3 cells were cultured in McCoy's medium with 5\% FBS. Cells were combined with each test drug and plated in 24 well plates at an initial density of 4,000 cells/well (MCF-7 and MDA-MB-231) or 5,000 cells/well (SK-BR-3). Drug concentrations ranged from $0-180 \mu \mathrm{g} / \mathrm{ml}$ for aspirin/aspirin-PC, and 0-50 $\mu \mathrm{M}$ for indomethacin/indomethacin-PC. Concentrations were selected based on previous studies that determined the toxic and therapeutic ranges for each drug $(5,6)$. Control wells of PC alone were run for each drug and cell line. Cells were incubated for 8 days at $37^{\circ} \mathrm{C}$ in $5 \%$ $\mathrm{CO}_{2}$, with one change of medium on day 4 . At least 4 replicate wells were plated for each drug and cell line.

MTT assay. On day 8, an MTT assay was performed in order to assess cell number. MTT reagent (Sigma-Aldrich; Merck $\mathrm{KGaA}$ ) was added to the wells at a concentration of $0.5 \mathrm{mg} / \mathrm{ml}$. Cells were then incubated for $4 \mathrm{~h}$ at $37^{\circ} \mathrm{C}$. MTT and culture medium were removed and a solvent (90\% isopropanol, $0.2 \%$ sodium dodecyl sulfate and $0.01 \mathrm{M} \mathrm{HCl}$ ) was added to extract the formazan product. The plates were read at $570 \mathrm{~nm}$. The average optical density reading for each well was converted to a ratio relative to untreated control wells from the same plate.

ELISA. Cell culture supernatant was collected on day 4 and assayed for prostaglandin E2 (PGE2) using the PGE2 ELISA kit-monoclonal from Cayman Chemical Company (cat. no. 514010). PGE2 activity was used as a marker of COX-2 activity.

Statistical analysis. Data are presented as the mean optical density reading relative to the untreated control. StatView software (version 5.01; SAS Institute Inc.) was used for the statistical analysis. One-way analysis of variance, with a Tukey-Kramer post-hoc test, was used to analyze the decrease in proliferation at each drug dosage vs. the untreated control, and to compare the decrease in cell proliferation as a result of each drug tested (NSAID, PC-NSAID and PC). $\mathrm{P}<0.05$ was considered to indicate a statistically significant difference. Significant decreases in proliferation relative to the control for each drug are indicated by an asterisk (*) in the figures. Significant differences between tested drugs are indicated by a caret $(\wedge)$ in the figures.

\section{Results}

MCF-7 (Luminal A) cell culture. MCF-7 cells, the estrogen receptor positive $(\mathrm{ER}+)$ /progesterone receptor positive $(\mathrm{PR}+)$ cell line, were unaffected by aspirin even at the highest concentration of $180 \mu \mathrm{g} / \mathrm{ml}$ (Fig. 1A). However, they were strongly inhibited by aspirin-PC at much lower doses. A control with PC alone demonstrated similar effectiveness, significantly reducing cell number even at the lowest dose of $5 \mu \mathrm{g} / \mathrm{ml}$. Thus, PC was determined to have a marked anti-tumor effect in this cell line, which potentially accounted for all the observed effects of aspirin-PC. According to the relative percentage of the decrease in cell number vs. control, indomethacin was the more effective of the two NSAIDs in the MCF-7 line across their respective dose ranges, with modest but significant reduction of cell number at doses as low as $12 \mu \mathrm{M}$, and an $\sim 50 \%$ decrease in cell number at the highest dose of $50 \mu \mathrm{M}$ (Fig. 1B). Indomethacin-PC was highly effective at limiting MCF-7 cell number, reaching a decrease of $58 \%$ at $8 \mu \mathrm{M}$ and almost complete elimination of cells at $50 \mu \mathrm{M}$. In contrast to the experiment with aspirin-PC, in which the PC-NSAID and PC alone showed very similar results, the effect of indomethacin-PC was greater than that of either the NSAID or PC alone. It is unclear whether the decreases in cell number caused by each drug are attributable to decreased proliferation, increased apoptosis or both.

MDA-MB-231 (triple negative) cell culture. MDA-MB-231, the triple negative cell line, exhibited a very similar response to MCF-7 in the aspirin experiments. Here, aspirin did cause a minimal decrease in cell number, but only reached a significant decrease at the highest dose of $180 \mu \mathrm{g} / \mathrm{ml}$ with $21 \%$ fewer cells than control (Fig. 2A). Again, both aspirin-PC and PC alone caused a similar and marked decrease in cell number even at low doses. Indomethacin was more effective than aspirin at its highest dose $(50 \mu \mathrm{M})$, leading to a $33 \%$ decrease in cell number, but had minimal and non-significant effects at lower doses. Indomethacin-PC was highly effective against MDA-MB-231 cells (Fig. 2B). A significant decrease in cell number was observed at doses as low as $3.2 \mu \mathrm{M}$, with a $78 \%$ decrease at the $50 \mu \mathrm{M}$ dose. As in the MCF-7 line, indomethacin-PC was substantially more effective than indomethacin or PC alone against the MDA-MB-231 tumor cells.

SK-BR-3 (HER2 enriched) cell culture. SK-BR-3 cells, the HER2/neu+ cell line, were the most responsive of the three cell lines to aspirin, with a $48 \%$ decrease in cell number at $180 \mu \mathrm{g} / \mathrm{ml}$ (Fig. 3A). This was also the only cell line in which aspirin-PC was more effective than either aspirin or PC alone, although this effect was not observed until doses of $72 \mu \mathrm{g} / \mathrm{ml}$ and above were reached. It was also the only cell line in which aspirin and aspirin-PC were more effective than indomethacin and indomethacin-PC, respectively, at their maximum doses (Fig. 3B). However, the effects of indomethacin were observed at lower concentrations, with significant decreases in cell number at doses as low as $8 \mu \mathrm{M}$ for indomethacin and $3.2 \mu \mathrm{M}$ for indomethacin-PC. Both PC-NSAIDs were more effective than the NSAID or PC alone in this cell line.

ELISA. In the ELISA assay, native expression of PGE2 was low for all cell lines, with values ranging from $5-30 \mathrm{pg} / \mathrm{ml}$ 
Table I. Characteristics of the breast cancer cell lines selected for use in the present study.

\begin{tabular}{lcccc}
\hline Cell line & Estrogen receptor & Progesterone receptor & HER2/neu amplification & Subtype term \\
\hline MCF-7 & + & + & - & Luminal A \\
SK-BR-3 & - & - & + & HER2-enriched \\
MDA-MB-231 & - & - & - & Triple negative
\end{tabular}

HER2, human epidermal growth factor receptor 2.
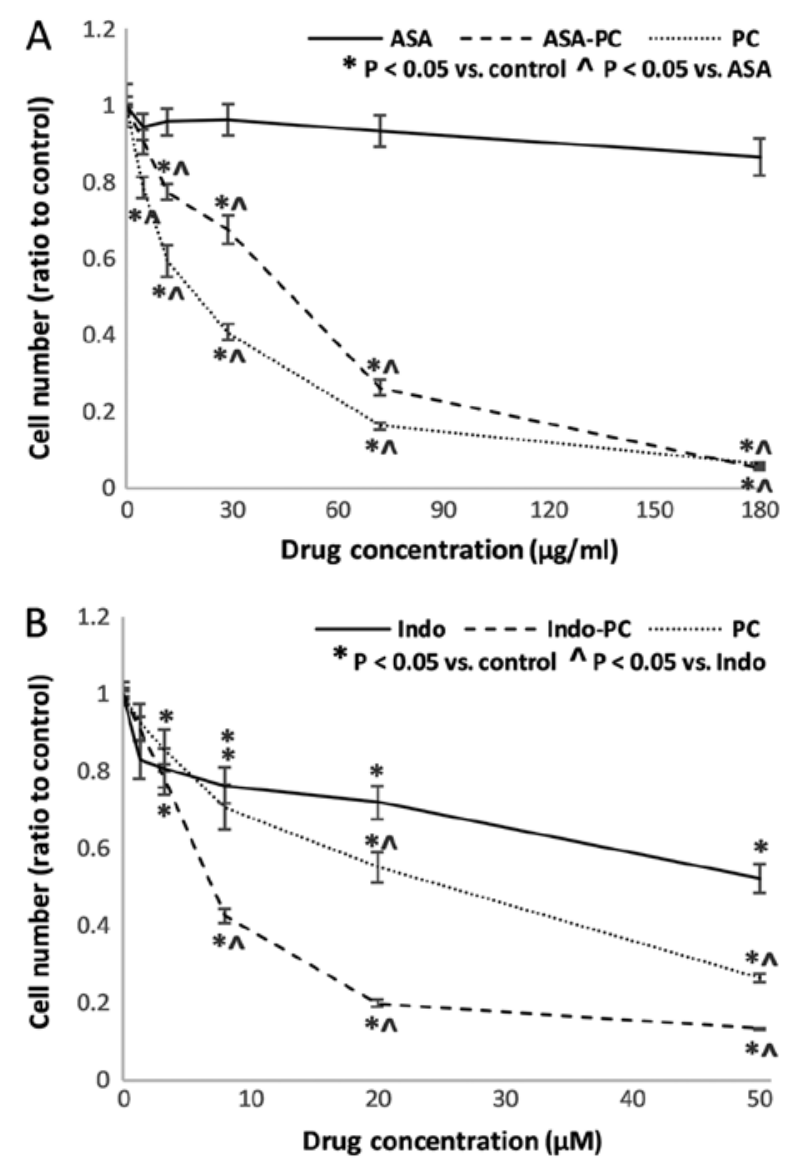

Figure 1. Effect of test drugs on MCF-7 (estrogen receptor positive/progesterone receptor positive/human epidermal growth factor receptor 2 negative) breast cancer cells in vitro. (A) The effect of aspirin, aspirin-PC and PC control. (B) The effect of indomethacin, indomethacin-PC and PC control. Error bars indicate standard error of the mean. ${ }^{*} \mathrm{P}<0.05$ vs. control ${ }^{\wedge} \mathrm{P}<0.05$ vs. NSAID alone. ASA, aspirin; Indo, indomethacin; PC, phosphatidylcholine.

of PGE2 in the collected supernatant. These values were at the low end of the ELISA sensitivity and could not be reliably distinguished from the background signal of the culture medium $+5 \%$ FBS. Thus, the variable effects of the drugs used on each cell line in the present study could not be attributed to their differences in COX expression or activity.

\section{Discussion}

The results from the present study are consistent with those from previous publications that demonstrated that NSAIDs and PC-NSAIDs inhibited the growth of colon, ovarian and
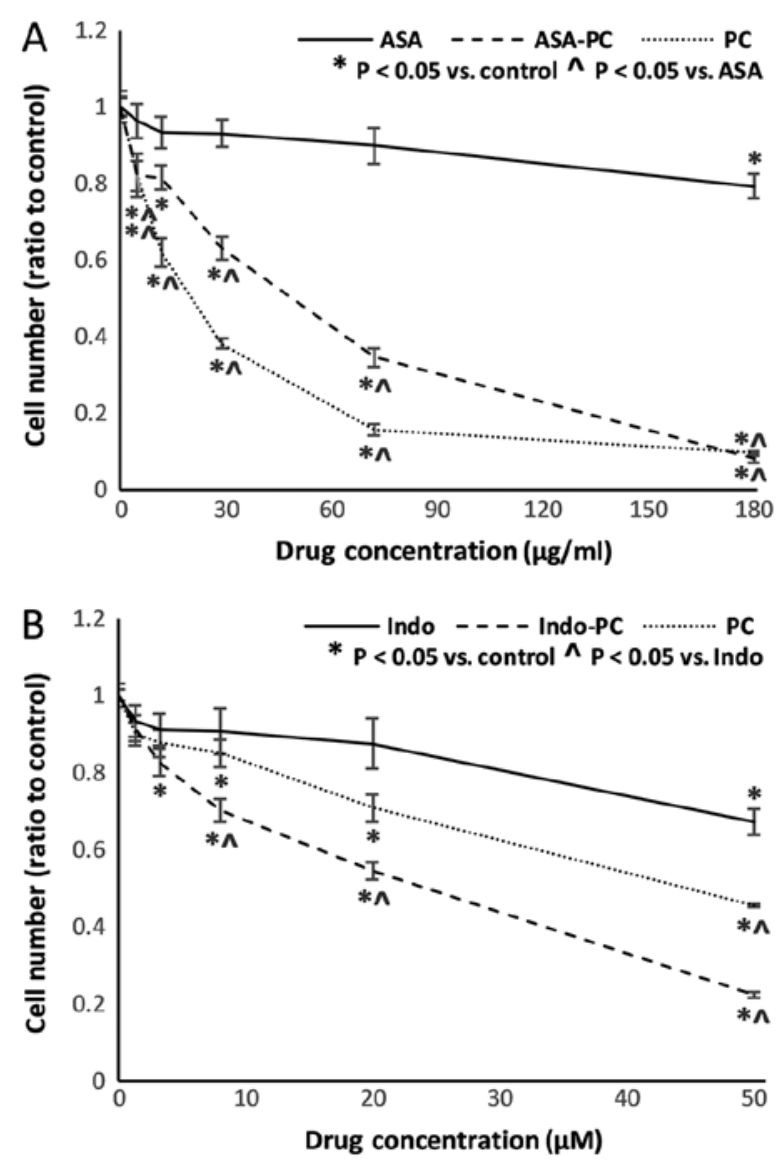

Figure 2. Effect of test drugs on MDA-MB-231 (estrogen receptor negative/progesterone receptor negative/human epidermal growth factor receptor 2 negative) breast cancer cells in vitro. (A) The effect of aspirin, aspirin-PC and PC control. (B) The effect of indomethacin, indomethacin-PC and $\mathrm{PC}$ control. Error bars indicate the standard error of the mean. ${ }^{*} \mathrm{P}<0.05$ vs. control; ${ }^{\wedge} \mathrm{P}<0.05$ vs. NSAID alone. ASA, aspirin; Indo, indomethacin; $\mathrm{PC}$, phosphatidylcholine.

pancreatic cancer cells in vitro $(5,6,23)$. As with the previous studies, PC-NSAIDs were more effective than the NSAID alone for all cell lines and drugs tested in the present study, and markedly so in certain cases. Furthermore, the results from the present study indicate that the PC component of the complexed drug possesses an independent anti-tumor action, resulting in an additive or synergistic drug effect, rather than PC serving merely to deliver the NSAIDs more efficiently to their site of action. Although PC-NSAIDs have not yet been evaluated in an in vivo model of breast cancer, PC-NSAIDs have, in certain cases, exhibited greater antitumorigenic effects than the NSAID alone in rodent models of colon and 

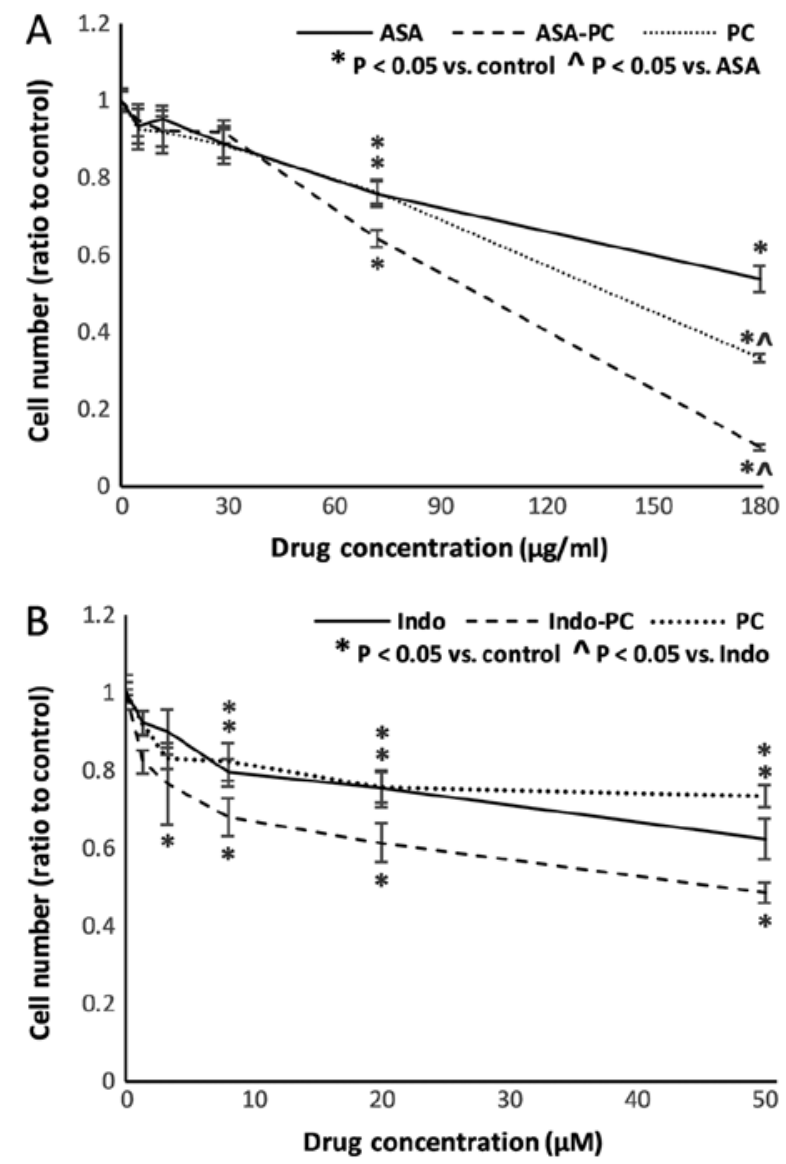

Figure 3. Effect of test drugs on SK-BR-3 (estrogen receptor negative/progesterone receptor negative/human epidermal growth factor receptor 2 positive) breast cancer cells in vitro. (A) The effect of aspirin, aspirin-PC and PC control. (B) The effect of indomethacin, indomethacin-PC and $\mathrm{PC}$ control. Error bars indicate the standard error of the mean. ${ }^{*} \mathrm{P}<0.05$ vs. control; ${ }^{\wedge} \mathrm{P}<0.05$ vs. NSAID alone. ASA, aspirin; Indo, indomethacin; $\mathrm{PC}$, phosphatidylcholine.

ovarian cancers $(5,6)$. PC-NSAIDs have an excellent safety profile in vivo, as demonstrated in both preclinical and clinical trials $(8,26-28)$. PC-NSAIDs have also been demonstrated as non-toxic to the non-cancerous gingival epithelium (29), suggesting a tumor-selective action. Indomethacin-PC looks particularly promising as a therapeutic agent in breast cancer since it was effective at a low dose in all three breast cancer cell lines, and it also exhibited a clear synergistic effect with the PC and drug components.

Although the results from the present study are quite promising, there were some limitations. First, the drugs used in the present study were not tested in vivo, although this will become the focus of future studies. The in vitro results from the present study, while suggestive, require additional evidence in order to be confirmed before being applied clinically. Secondly, the present study was designed with a single incubation time of 8 days based on previous successful results studying non-breast cancer cell lines $(5,6)$. This method does not allow the assessment of time dependency of the cells' response to the test drugs over the course of the experiment. Finally, a control line representing normal cells was not included due to concerns that the available lines were not truly representative of normal cells and could not be accurately compared with tumor lines. Immortalized cells, such as the MCF10A cell line, possess genetic modifications that are typical of cancer cells rather than normal cells, including telomerase activation (30), and the MCF10A line was demonstrated to be phenotypically unrepresentative of normal mammary tissue (31). Both immortalized and primary cell lines require potent growth factors not present in tumor cell media, limiting comparisons. As an appropriate control was unavailable, it is not known how normal mammary cells would respond to the drugs tested in the present study. Further research, particularly in vivo trials, will be instrumental to address these unresolved questions and further assess the clinical utility of the tested drugs in breast cancer treatment.

The activity of NSAIDs against breast cancer is traditionally attributed to inhibition of the COX-2 enzyme, which is overexpressed in certain forms of breast tumor (32) and may be associated with poor prognosis (33-35). However, the results from the ELISA in the present and previous experiments have not convincingly demonstrated a dominant role for COX inhibition, despite the effectiveness of the drugs in limiting tumor cell number (5). In the Nurses' Health Study, the survival benefit of aspirin was revealed to be independent of COX-2 expression in breast tumors (35). A number of COX-independent mechanisms for the chemopreventive and chemotherapeutic effects of NSAIDs have been proposed (36). For example, indomethacin can modify the behavior of cell membranes, potentially affecting intracellular signaling pathways (37). Sulindac and other NSAIDs have demonstrated proapoptotic and antiangiogenic effects via non-COX-mediated mechanisms (36). In addition, new evidence has suggested that the ability of aspirin to decrease breast cancer invasion and metastasis may be platelet-mediated (38). This coincides with a previous study, which demonstrated that activated platelets increased proliferation of colon cancer in both in vitro and in vivo mouse models, while treatment with aspirin and aspirin-PC decreased platelet counts and activation, which was correlated with decreased tumor burden (24). Platelet effects may account for the apparent effectiveness of aspirin against breast cancer in epidemiological studies despite the minimal direct antitumor effect of the drug in previous in vitro studies, which were performed in the absence of platelets $(5,6,39)$. The authors of the present study aim to investigate the role of platelets and NSAID-induced platelet inhibition in breast cancer in future projects.

The significant and consistent anti-tumor activity of phosphatidylcholine in the present study was unanticipated. PC is commonly used to prepare liposomes for the delivery of drugs, including chemotherapeutic agents, under the assumption that liposomes may help the drug reach its target tissue while minimizing systemic toxicity (40). However, the majority of currently published studies have not used empty liposomes as a control; a few have attempted this and demonstrated that liposomes composed of PC alone exhibited independent antitumor activity $(41,42)$. For example, empty PC liposomes decreased tumor size and metastasis in a mouse model of pancreatic cancer (41). In another study, liposomes containing PC and the omega-3 fatty acid docosahexaenoic acid decreased metastases from colon and hepatic cancer in mice (42). Dietary PC was also observed to inhibit the growth of hepatocellular carcinoma in rats by inducing apoptosis, without impairing liver function (43). The mechanism underlying the potential anti-tumor 
effect of PC is currently unclear, but may be attributable to affecting the activity of phospholipase enzymes, including phospholipase A2 (PLA2), which is highly expressed in certain types of breast cancer $(44,45)$. PC cleavage by PLA2 generates lyso-PC, which is cytotoxic in high concentrations $(46,47)$ and may accumulate differentially around PC-exposed tumor cells due to their excessive enzyme activity. High concentrations of PC may also modify cellular activity by altering membrane fluidity and signaling pathways (48-51). Abnormal phospholipase signaling is known to play a key role in tumorigenesis in a number of different types of cancer, and has been suggested as a promising pathway for pharmaceutical intervention (52). PC may open up this potential, particularly when used in combination with other effective drugs, such as NSAIDs.

\section{Acknowledgements}

The authors would like to thank Dr Dexing Fang from the McGovern Medical School at UTHealth (Houston, USA), who assisted with the ELISA procedures and advised on cell culture techniques, and Dr Elizabeth J. Dial from the McGovern Medical School at UTHealth (Houston, USA), who advised on drug preparation and interpretation of the results.

\section{Funding}

The present study was funded with discretionary funds from the authors.

\section{Availability of data and materials}

The datasets used and/or analyzed during the present study are available from the corresponding author upon reasonable request.

\section{Authors' contributions}

LL designed and directed the present study in consultation with SB, interpreted the results and contributed to writing the article. SB performed the cell cultures, ELISA, statistical analyses and was the primary author of the article.

\section{Ethics approval and consent to participate}

Not applicable.

\section{Patient consent for publication}

Not applicable.

\section{Competing interests}

LL is a co-founder and shareholder in PLx Pharma Inc., which is developing PC-NSAIDs for commercial use. SB has declared no competing interests.

\section{References}

1. Rothwell PM, Fowkes FG, Belch JF, Ogawa H, Warlow CP and Meade TW: Effect of daily aspirin on long-term risk of death due to cancer: Analysis of individual patient data from randomised trials. Lancet 377: 31-41, 2011.
2. Rothwell PM, Wilson M, Price JF, Belch JF, Meade TW and Mehta Z: Effect of daily aspirin on risk of cancer metastasis: A study of incident cancers during randomised controlled trials. Lancet 379: 1591-1601, 2012.

3. Mills EJ, Wu P, Alberton M, Kanters S, Lanas A and Lester R: Low-dose aspirin and cancer mortality: A meta-analysis of randomized trials. Am J Med 125: 560-567, 2012.

4. Algra AM and Rothwell PM: Effects of regular aspirin on long-term cancer incidence and metastasis: A systematic comparison of evidence from observational studies versus randomised trials. Lancet Oncol 13: 518-527, 2012.

5. Lichtenberger LM, Phan T, Fang D and Dial EJ: Chemoprevention with phosphatidylcholine non-steroidal anti-inflammatory drugs in vivo and in vitro. Oncol Lett 15: 6688-6694, 2018.

6. Huang Y, Lichtenberger LM, Taylor M, Bottsford-Miller JN, Haemmerle M, Wagner MJ, Lyons Y, Pradeep S, Hu W, Previs RA, et al: Antitumor and antiangiogenic effects of aspirin-PC in ovarian cancer. Mol Cancer Ther 15: 2894-2904, 2016.

7. Dial E, Doyen JR and Lichtenberger LM: Phosphatidylcholineassociated nonsteroidal anti-inflammatory drugs (NSAIDs) inhibit DNA synthesis and the growth of colon cancer cells in vitro. Cancer Chemother Pharmacol 57: 295-300, 2006.

8. Cryer B, Bhatt DL, Lanza FL, Dong JF, Lichtenberger LM and Marathi UK: Low-dose aspirin-induced ulceration is attenuated by Aspirin-Phosphatidylcholine: A randomized clinical trial. Am J Gastroenterol 106: 272-277, 2011.

9. Takkouche B, Regueira-Méndez C and Etminan M: Breast cancer and use of nonsteroidal anti-inflammatory drugs: A meta-analysis. J Natl Cancer Inst 100: 1439-1447, 2008.

10. Holmes MD, Chen WY, Li L, Hertzmark E, Spiegelman D and Hankinson SE: Aspirin intake and survival after breast cancer. J Clin Oncol 28: 1467-1472, 2010.

11. Fraser DM, Sullivan FM, Thompson AM and Mccowan C: Aspirin use and survival after the diagnosis of breast cancer: A population-based cohort study. Br J Cancer 111: 623-627, 2014.

12. Egan KM, Stampfer MJ, Giovannucci E, Rosner BA and Colditz GA: Prospective study of regular aspirin use and the risk of breast cancer. J Natl Cancer Inst 88: 988-993, 1996.

13. Menamin ÚM, Cardwell C, Hughes C and Murray L: Low-dose aspirin use and survival in breast cancer patients: A nationwide cohort study. Cancer Epidemiol 48: 158, 2017.

14. Add-aspirin: A trial assessing the effects of aspirin on disease recurrence and survival after primary therapy in common non metastatic solid tumours status: Recruiting. First posted 2017. ClinicalTrials.gov identifier: NCT02804815.https://clinicaltrials. gov/ct2/show/NCT02804815.

15. Aspirin in preventing recurrence of cancer in patients with HER2 negative stage II-III breast cancer after chemotherapy, surgery, and/or radiation therapy status: Recruiting. First posted 2016. ClinicalTrials.gov identifier: NCT02927249. https://clinicaltrials.gov/ct2/show/NCT02927249.

16. Low dose chemotherapy with aspirin in patients with breast cancer after neoadjuvant chemotherapy status: Unknown status. First posted 2012. ClinicalTrials.gov identifier: NCT01612247. https://clinicaltrials.gov/ct2/show/NCT01612247.

17. Kennedy BM and Harris RE: Cyclooxygenase and lipoxygenase gene expression in the inflammogenesis of breast cancer. Inflammopharmacology 2018 (Epub ahead of print).

18. Liu XH and Rose DP: Differential expression and regulation of cyclooxygenase-1 and -2 in two human breast cancer cell lines. Cancer Res 56: 5125-5127, 1996.

19. Clarke CA, Canchola AJ, Moy LM, Neuhausen SL, Chung NT, Lacey JV Jr and Bernstein L: Regular and low-dose aspirin, other non-steroidal anti-inflammatory medications and prospective risk of HER-2 defined breast cancer: The california teachers study. Breast Cancer Res 19: 52, 2017.

20. Marshall SF, Bernstein L, Anton-Culver H, Deapen D, Horn-Ross PL, Mohrenweiser H, Peel D, Pinder R, Purdie DM, Reynolds P, et al: Nonsteroidal anti-inflammatory drug use and breast cancer risk by stage and hormone receptor status. J Natl Cancer Inst 97: 805-812, 2005.

21. Zhang X, Smith-Warner SA, Collins LC, Rosner B, Willett WC and Hankinson SE: Use of aspirin, other nonsteroidal anti-inflammatory drugs, and acetaminophen and postmenopausal breast cancer incidence. J Clin Oncol 30: 3468-3477, 2012.

22. Amaral MEA, Nery LR, Leite CE, de Azevedo Junior WF and Campos MM: Pre-clinical effects of metformin and aspirin on the cell lines of different breast cancer subtypes. Invest New Drugs 36: 782-796, 2018. 
23. Gupta R, Fang D and Lichtenberger LM: Mo1985-evaluation of the inhibitory efficacy and potency of PC-NSAIDs on pancreatic cancer cells in culture. Gastroenterol 154 (Suppl 6): S-872, 2018.

24. Lichtenberger LM, Fang D, Bick RJ, Poindexter BJ, Phan T, Bergeron AL, Pradhan S, Dial EJ and Vijayan KV: Unlocking aspirin's chemopreventive activity: Role of irreversibly inhibiting platelet cyclooxygenase-1. Cancer Prev Res (Phila) 10: 142-152, 2017.

25. Lichtenberger LM: Purified phospholipid-non-steroidal anti-inflammatory drug associated compositions and methods for preparing and using same. US patent 8,802,656 B2. Filed October 12, 2005; issued August 12, 2014.

26. Lichtenberger LM, Wang ZM, Romero JJ, Ulloa C, Perez JC, Giraud MN and Barreto JC: Non-steroidal anti-inflammatory drugs (NSAIDs) associate with zwitterionic phospholipids: Insight into the mechanism and reversal of NSAID-induced gastrointestinal injury. Nat Med 1: 154-158, 1995.

27. Lichtenberger L, Romero JJ and Dial EJ: Gastrointestinal safety and therapeutic efficacy of parenterally administered phosphatidylcholine-associated indomethacin in rodent model systems. Br J Pharmacol 157: 252-257, 2009.

28. Lanza FL, Marathi UK, Anand BS and Lichtenberger LM: Clinical trial: Comparison of ibuprofen-phosphatidylcholine and ibuprofen on the gastrointestinal safety and analgesic efficacy in osteoarthritic patients. Aliment Pharmacol Ther 28: 431-442, 2008.

29. Lichtenberger LM, Dial EJ and Fang D: Use of PC-NSAIDs to protect gingival cells from injury due to cytotoxic agents. FASEB J 31: 993.9-993.9, 2017.

30. Qu Y, Han B, Yu Y, Yao W, Bose S, Karlan BY, Giuliano AE and Cui X: Evaluation of MCF10A as a reliable model for normal human mammary epithelial cells. PLoS One 10: e0131285, 2015.

31. Newbold RF: The significance of telomerase activation and cellular immortalization in human cancer. Mutagenesis 17: 539-550, 2002.

32. Howe LR: Inflammation and breast cancer. Cyclooxygenase/prostaglandin signaling and breast cancer. Breast Cancer Res 9: 210, 2007.

33. Chikman B, Vasyanovich S, Lavy R, Habler L, Tolstov G, Kapiev A, Halevy A and Sandbank J: COX2 expression in high-grade breast cancer: Evidence for prognostic significance in the subset of triple-negative breast cancer patients. Med Oncol 31: 989, 2014

34. Ristimäki A, Sivula A, Lundin J, Lundin M, Salminen T, Haglund C, Joensuu $\mathrm{H}$ and Isola J: Prognostic significance of elevated cyclooxygenase- 2 expression in breast cancer. Cancer Res 62: 632-635, 2002.

35. Holmes MD, Chen WY, Schnitt SJ, Collins L, Colditz GA, Hankinson SE and Tamimi RM: COX-2 expression predicts worse breast cancer prognosis and does not modify the association with aspirin. Breast Cancer Res Treat 130: 657-662, 2011.

36. Gurpinar E, Grizzle WE and Piazza GA: NSAIDs inhibit tumorigenesis, but how? Clin Cancer Research 20: 1104-1113, 2014

37. Zhou Y, Plowman SJ, Lichtenberger LM and Hancock JF: The anti-inflammatory drug indomethacin alters nanoclustering in synthetic and cell plasma membranes. J Biol Chem 285: 35188-35195, 2010.

38. Johnson KE, Ceglowski JR, Roweth HG, Forward JA, Tippy MD, El-Husayni S, Kulenthirarajan R, Malloy MW, Machlus KR, Chen WY, et al: Aspirin inhibits platelets from reprogramming breast tumor cells and promoting metastasis. Blood Adv 3: 198-211, 2019.
39. Lichtenberger LM and Vijayan KV: Are platelets the primary target of aspirin's remarkable anticancer activity? Cancer Res 79: 3820-3823, 2019.

40. Sercombe L, Veerati T, Moheimani F, Wu SY, Sood AK and Hua S: Advances and challenges of liposome assisted drug delivery. Front Pharmacol 6: 286, 2015.

41. Graeser R, Bornmann C, Esser N, Ziroli V, Jantscheff P, Unger C, Hopt UT, Schaechtele C, Von Dobschuetz E and Massing U: Antimetastatic effects of liposomal gemcitabine and empty liposomes in an orthotopic mouse model of pancreatic cancer. Pancreas 38: 330-337, 2009.

42. Ichihara H, Zako K, Komizu Y, Goto K and Ueoka R: Therapeutic effects of hybrid liposomes composed of phosphatidylcholine and docosahexaenoic acid on the hepatic metastasis of colon carcinoma along with apoptosis in vivo. Biol Pharm Bull 34: 901-905, 2011.

43. Sakakima Y, Hayakawa A, Nagasaka T and Nakao A: Prevention of hepatocarcinogenesis with phosphatidylcholine and menaquinone-4: In vitro and in vivo experiments. J Hepatol 47: 83-92, 2007.

44. Steiner MR: Localization and characterization of phospholipase A2 in mouse mammary gland derived cells. Arch Biochem Biophys 286: 293-299, 1991.

45. Rillema JA, Osmialowski EC and Linebaugh BE: Phospholipase A 2 activity in 9,10-dimethyl-1,2-benzanthracene-induced mammary tumors of rats. Biochim Biophys Acta 617: 150-155, 1980.

46. Lutz J, Augustin AJ, Jäger LJ, Bachmann D and Brandl M: Acute toxicity and depression of phagocytosis in vivo by liposomes: Influence of lysophosphatidylcholine. Life Sci 56: 99-106, 1995.

47. Chang MC, Lee JJ, Chen YJ, Lin SI, Lin LD, Jein-Wen Liou E, Huang WL, Chan CP, Huang CC and Jeng JH: Lysophosphadylcholine induces cytotoxicity/apoptosis and IL-8 production of human endothelial cells: Related mechanisms. Oncotarget 8: 106177-106189, 2017.

48. Barenholz Y: Sphingomyelin-lecithin balance in membranes: Composition, structure and function relationships. In: Physiology of Membrane Fluidity (Vol. 1). Shinitzky M (ed.) CRC Press, Florida, pp131-174, 1984

49. Cossins AR and Sinensky M: Adaptation of membranes to temperature, pressure and exogenous lipids. In: Physiology of Membrane Fluidity (Vol. 2). Shinitzky M (ed.) CRC Press, Florida, pp1-20, 1984.

50. Van Blitterswijk WJ: Alterations in lipid fluidity in the plasma membrane of tumor cells. In: In: Physiology of Membrane Fluidity (Vol. 2). Shinitzky M (ed.) CRC Press, Florida, pp53-84, 1984

51. Lichtenberger LM, Zhou Y, Jayaraman V, Doyen JR, O'Neil RG, Dial EJ, Volk DE, Gorenstein DG, Boggara MB and Krishnamoorti R: Insight into NSAID-induced membrane alterations, pathogenesis and therapeutics: Characterization of interaction of NSAIDs with phosphatidylcholine. Biochim Biophys Acta 1821: 994-1002, 2012.

52. Park JB, Lee CS, Jang JH, Ghim J, Kim YJ, You S, Hwang D, Suh PG and Ryu SH: Phospholipase signalling networks in cancer. Nat Rev Cancer 12: 782-792, 2012. 